\title{
In Vitro and In Vivo Evaluation of Voriconazole-Containing Antifungal Combinations against Mucorales Using a Galleria mellonella Model of Mucormycosis
}

\author{
Daiana Macedo ${ }^{1}$, Florencia Leonardelli ${ }^{1}$, Catiana Dudiuk ${ }^{1}$, Roxana G. Vitale ${ }^{2}$, \\ Eleodoro Del Valle ${ }^{3}$, Gustavo Giusiano $\left.{ }^{4}{ }^{(}\right)$, Soledad Gamarra ${ }^{5}$ and Guillermo Garcia-Effron ${ }^{1, *}$ \\ 1 Consejo Nacional de Investigaciones Científicas y Tecnológicas CONICET, Laboratorio de Micología y \\ Diagnóstico Molecular-Cátedra de Parasitología y Micología-Facultad de Bioquímica y Ciencias \\ Biológicas-Universidad Nacional del Litoral, Santa Fe CP 3000, Argentina; \\ daiana.magalimacedo@gmail.com (D.M.); leonardellifs@gmail.com (F.L.); cbdudiuk@gmail.com (C.D.) \\ 2 Unidad de Parasitología, Laboratorio de Micología, Hospital Ramos Mejía, CONICET, \\ Ciudad Autónoma de Buenos Aires CP1221, Argentina; Roxana_vitale@yahoo.com \\ 3 Facultad de Ciencias Agrarias, Universidad Nacional del Litoral, Esperanza CP3080, Argentina; \\ eleodoro77@gmail.com \\ 4 Consejo Nacional de Investigaciones Científicas y Tecnológicas CONICET, Área Micología, \\ Instituto de Medicina Regional, Universidad Nacional del Nordeste, Resistencia CP3500, Argentina; \\ gustavogiusiano@yahoo.com.ar \\ 5 Laboratorio de Micología y Diagnóstico Molecular-Cátedra de Parasitología y Micología—Facultad de \\ Bioquímica y Ciencias Biológicas-Universidad Nacional del Litoral, Santa Fe CP3000, Argentina; \\ mgamarra@fbcb.unl.edu.ar \\ * Correspondence: ggarcia@unl.edu.ar; Tel.: +54-342-4575209 (ext. 135); Fax: +54-342-4575216
}

Received: 2 December 2018; Accepted: 6 January 2019; Published: 8 January 2019

\begin{abstract}
Mucorales are resistant to most antifungals. Mucormycosis associated mortality is unacceptable and new treatment approaches are needed. The objectives of this work were (i) to evaluate the nature and intensity of the in vitro effect of three drugs combinations which included voriconazole (plus amphotericin B, posaconazole and caspofungin) against 25 strains of six different Mucorales species; (ii) to evaluate a Galleria mellonella mucormycosis model; and (iii) to establish if any in vitro-in vivo correlation exists. As expected, amphotericin B and posaconazole were the most active drugs when tested alone. However, species-specific differences were found. The $\Sigma$ FICs varied according to the used combination. Only five strains showed synergism when voriconazole was combined with posaconazole and three strains when combined with amphotericin B. Microscopic hyphae alteration were observed for some isolates when confronted against drugs combinations. Using a Galleria mellonella mucormycosis model, better survival was seen in voriconazole plus amphotericin B and plus caspofungin combined treatments when compared with AMB alone for R. microsporus. These survival improvements were obtained using a 32-fold lower amphotericin B doses when combined with VRC than when treated with the polyene alone. These lower antifungal doses emulate the antifungal concentrations where the microscopic hyphae alterations were seen.
\end{abstract}

Keywords: mucormycosis; Galleria mellonella; synergism; azole; voriconazole; amphotericin B

\section{Introduction}

Mucormycosis is a rapidly progressing fungal infection with high morbidity and mortality rates. It is considered a therapeutic challenge since Mucorales are resistant to most antifungals. 
For many years, amphotericin B (AMB) has been the only available drug to treat these mycoses. Later, posaconazole (PSC) and more recently isavuconazole were added to the antifungal armamentarium as step-down and salvage therapy [1,2]. Despite these advances, mortality is still unacceptable and, clearly, new approaches are needed [3]. These facts have stimulated the interest in studying combinations of antifungal agents to determine if they could achieve better results. Spellberg et al. described the reasons for studying a particular combination therapy for Mucormycosis [4], including agents already approved for use in humans, which improve survival in animal models and known to be effective and safe. Following these premises, several reports were published with variable results. Most of them, describing the effectiveness of different combinations assessed empirically (tested in vivo without a previous in vitro evaluation) using murine models of infection. These studies included combinations of $\mathrm{AMB}$ with different echinocandins and/or iron chelators and the combination of azole (in vitro active against Mucorales as isavuconazole and PSC) with echinocandins and calcineurin inhibitors [5-11]. However, most of these studies do not include species and/or variety identifications, nor do they use drug combinations previously evaluated in vitro nor have combinations that include voriconazole been tested. The objectives of this work were (i) to evaluate the nature and the intensity of the in vitro effect of drug combinations including voriconazole (VRC) plus AMB, PSC, and caspofungin (CSF) against six different Mucorales species; (ii) to evaluate a Galleria mellonella model of mucormicosis; and (iii) to determine if any in vitro-in vivo correlation exists.

\section{Materials and Methods}

\subsection{Fungal Isolates}

Twenty-five Mucorales isolates, including 15 Rhizopus microsporus (12 formerly considered as var. rhizopodiformis and 3 as var. microsporus) [12], 3 Rhizopus oryzae, 4 Syncephalastrum racemosum, 1 Lichthemia corymbifera, 1 Lichthemia blakesleeana, and 1 Lichethemia ramosa, were studied. Of those, 19 strains have clinical origin including rhinocerebral mucormycosis $(n=9)$, osteomyelitis $(n=5)$, surgical wound infection $(n=3)$, cutaneous ulcer $(n=1)$ and one with no isolation site data (Table 1$)$. Candida parapsilosis sensu stricto ATCC 22019 and C. krusei ATCC 6258 were used as control isolates for susceptibility testing. Strains were identified by morphological, physiological and molecular criteria. The morphology and the relative position of the strain's sporangium, aphophysis and columella were analyzed [13-15]. Molecular identification was done by a PCR-RFLP [16] and by internal transcribed spacer 1 and 2 regions (ITS1 and ITS2) sequencing [17-19]. Thermotolerance (radial growth measurement after $120 \mathrm{~h}$ of incubation at $50^{\circ} \mathrm{C}$ ) was used to differentiate $R$. microsporus former varieties since molecular methods are unable to do so $[14,15]$. 
Table 1. Antifungal susceptibility, $\Sigma F I C$ indexes, and microscopic alteration of hyphae in combination wells of the studied Mucorales isolates

\begin{tabular}{|c|c|c|c|c|c|c|c|c|c|c|c|c|}
\hline \multirow{3}{*}{ Isolate $\mathbf{N}^{\circ}$} & \multirow{3}{*}{ Organism } & \multirow{3}{*}{ Isolation Site } & \multirow{2}{*}{\multicolumn{4}{|c|}{ MIC (mg/L) }} & \multicolumn{6}{|c|}{$\sum$ FIC Index (Interpretation) $^{c}$} \\
\hline & & & & & & & \multicolumn{2}{|c|}{ VRC + PSC } & \multicolumn{2}{|c|}{ VRC + AMB } & \multicolumn{2}{|c|}{ VRC + CSF } \\
\hline & & & VRC & PSC & AMB & CSF & MIC & HA & MIC & HA & MIC & HA \\
\hline LMDM-165 & R. microsporus a & Osteomyelitis & 8.00 & 1.00 & 2.00 & 16.00 & $0.75(\mathrm{NI})$ & Yes & $0.75(\mathrm{NI})$ & Yes & $0.75(\mathrm{NI})$ & Yes \\
\hline LMDM-156 & R. microsporus a & Osteomyelitis & 4.00 & 1.00 & 2.00 & 16.00 & 1.00 (NI) & Yes & $2.04(\mathrm{NI})$ & No & 1.00 (NI) & Yes \\
\hline LMDM-157 & R. microsporus a & Surgical wound & 4.00 & 0.50 & 1.00 & 16.00 & $0.50(\mathrm{~S})$ & Yes & $1.03(\mathrm{NI})$ & No & 0.75 (NI) & Yes \\
\hline LMDM-158 & R. microsporus a & Surgical wound & 8.00 & 0.50 & 2.00 & 16.00 & $1.00(\mathrm{NI})$ & Yes & $1.04(\mathrm{NI})$ & No & $2.00(\mathrm{NI})$ & Yes \\
\hline LMDM-159 & R. microsporus a & Surgical wound & 4.00 & 1.00 & 2.00 & 16.00 & $1.00(\mathrm{NI})$ & No & $1.03(\mathrm{NI})$ & No & $1.50(\mathrm{NI})$ & No \\
\hline LMDM-164 & R. microsporus a & Osteomyelitis & 4.00 & 1.00 & 2.00 & 16.00 & 1.00 (NI) & No & 1.01 (NI) & Yes & 1.00 (NI) & No \\
\hline LMDM-167 & R. microsporus a & Hospital environment & 4.00 & 1.00 & 2.00 & 16.00 & $1.02(\mathrm{NI})$ & Yes & $1.03(\mathrm{NI})$ & No & 1.25 (NI) & No \\
\hline LMDM-168 & R. microsporus a & Hospital environment & 4.00 & 1.00 & 2.00 & 16.00 & $1.03(\mathrm{NI})$ & No & $2.50(\mathrm{NI})$ & No & $2.00(\mathrm{NI})$ & No \\
\hline LMDM-176 & R. microsporus a & Osteomyelitis & 8.00 & 1.00 & 2.00 & 16.00 & $0.63(\mathrm{NI})$ & Yes & $2.25(\mathrm{NI})$ & Yes & $1.25(\mathrm{NI})$ & No \\
\hline LMDM-184 & R. microsporus a & Osteomyelitis & 8.00 & 1.00 & 2.00 & 16.00 & $0.75(\mathrm{NI})$ & Yes & $1.03(\mathrm{NI})$ & Yes & $1.03(\mathrm{NI})$ & No \\
\hline LMDM-379 & R. microsporus a & Rhinocerebral & 8.00 & 1.00 & 4.00 & 16.00 & 0.63 (NI) & Yes & 1.00 (NI) & No & 0.75 (NI) & Yes \\
\hline LMDM-596 & R. microsporus a & Rhinocerebral & 2.00 & 1.00 & 1.00 & 16.00 & $1.06(\mathrm{NI})$ & No & $2.00(\mathrm{NI})$ & No & $1.03(\mathrm{NI})$ & No \\
\hline LMDM-1073 & R. microsporus ${ }^{\mathrm{b}}$ & Rhinocerebral & 2.00 & 1.00 & 0.50 & 16.00 & $1.06(\mathrm{NI})$ & No & $1.06(\mathrm{NI})$ & No & $2.00(\mathrm{NI})$ & No \\
\hline LMDM-1074 & R. microsporus ${ }^{b}$ & Rhinocerebral & 2.00 & 1.00 & 0.25 & 16.00 & $0.75(\mathrm{NI})$ & No & $0.62(\mathrm{NI})$ & No & 2.00 (NI) & No \\
\hline LMDM-1127 & R. microsporus $\mathrm{b}$ & Hospital environment & 8.00 & 2.00 & 1.00 & 16.00 & $0.50(\mathrm{~S})$ & No & $0.50(\mathrm{~S})$ & No & $0.75(\mathrm{NI})$ & No \\
\hline$n=15$ & R. microsporus & & 4.59 & 0.95 & 1.45 & 16.00 & 0.82 & & 1.14 & & 1.18 & \\
\hline LMDM-597 & R. oryzae & Rhinocerebral & 8.00 & 1.00 & 2.00 & 16.00 & $0.75(\mathrm{NI})$ & No & $0.75(\mathrm{NI})$ & No & $0.75(\mathrm{NI})$ & No \\
\hline LMDM-1126 & R. oryzae & Rhinocerebral & 8.00 & 1.00 & 1.00 & 16.00 & $0.75(\mathrm{NI})$ & No & $0.50(\mathrm{~S})$ & No & $1.00(\mathrm{NI})$ & No \\
\hline LMDM-1075 & R. oryzae & Rhinocerebral & 4.00 & 1.00 & 0.25 & 16.00 & 1.00 (NI) & No & $0.62(\mathrm{NI})$ & No & 2.00 (NI) & No \\
\hline$n=3$ & R. oryzae & & 6.35 & 1.00 & 0.79 & 16.00 & 0.83 & & 0.61 & & 1.14 & \\
\hline LMDM-1122 & S. racemosum & Rhinocerebral & 4.00 & 1.00 & 0.50 & 16.00 & $1.00(\mathrm{NI})$ & Yes & $1.00(\mathrm{NI})$ & Yes & $2.00(\mathrm{NI})$ & Yes \\
\hline LMDM-1123 & S. racemosum & Hospital environment & 4.00 & 1.00 & 0.25 & 16.00 & 0.75 (NI) & No & 1.00 (NI) & No & 2.00 (NI) & Yes \\
\hline LMDM-1124 & S. racemosum & Hospital environment & 16.00 & 2.00 & 0.50 & 16.00 & $1.00(\mathrm{NI})$ & No & $1.00(\mathrm{NI})$ & No & $2.00(\mathrm{NI})$ & No \\
\hline LMDM-576 & S. racemosum & Rhinocerebral & 16.00 & 2.00 & 2.00 & 16.00 & $0.50(\mathrm{~S})$ & Yes & $0.50(\mathrm{~S})$ & Yes & $1.00(\mathrm{NI})$ & Yes \\
\hline$n=4$ & S. racemosum & & 8.00 & 1.40 & 0.59 & 16.00 & 0.78 & & 0.88 & & 1.75 & \\
\hline LMDM-1128 & L. blakesleeana & Cutaneous ulcera & 4.00 & 0.50 & 0.50 & 16.00 & $0.75(\mathrm{NI})$ & Yes & $1.00(\mathrm{NI})$ & Yes & $2.00(\mathrm{NI})$ & No \\
\hline LMDM-1121 & L. corymbifera & Hospital environment & 8.00 & 1.00 & 0.25 & 16.00 & $0.50(\mathrm{~S})$ & Yes & $1.00(\mathrm{NI})$ & No & $2.00(\mathrm{NI})$ & Yes \\
\hline LMDM-1125 & L. ramosa & Clinical d $^{\mathrm{d}}$ & 16.00 & 1.00 & 1.00 & 16.00 & $0.31(\mathrm{~S})$ & No & $0.62(\mathrm{NI})$ & No & 1.00 (NI) & No \\
\hline$n=3$ & Lichtheimia spp. & & 8.00 & 0.80 & 0.50 & 16.00 & 0.49 & & 1.09 & & 1.45 & \\
\hline$n=25$ & Mucormycetes & & 5.74 & 1.03 & 1.03 & 16.00 & 0.81 & & 1.09 & & 1.45 & \\
\hline$n=10$ & non-R. microsporus & & 8.00 & 1.15 & 0.62 & 16.00 & 0.73 & & 0.80 & & 1.70 & \\
\hline
\end{tabular}

${ }^{a}$ Formerly classified as R. microsporus var. rhizopodiformis (thermotolerant) [12]. ${ }^{b}$ Formerly classified as R. microsporus var. microsporus (less thermotolerant) [12]. ${ }^{\mathrm{c}} \mathrm{HA}$ : hyphal alterations were seen in wells where antifungals were combined. (S) synergism. (NI) No interaction. ${ }^{\mathrm{d}}$ No isolation site data available. Lines in the table highlighted in grey show the MIC Geometric means and the $\Sigma$ FIC indexes arithmetic means per group of Mucorales species/genus. 


\subsection{Susceptibility Testing for Individual Drugs and Combination of Drugs}

The MICs values of VRC, AMB, CSF, and PSC (all obtained from Sigma-Aldrich, Buenos Aires, Argentina) were obtained following the CLSI M38 3rd edition protocol [20]. Drug interactions were evaluated by a two-dimensional checkerboard microdilution technique using the drug concentration ranges, inoculum, media, and incubation conditions of the same CLSI protocol [20]. The nature and intensity of drugs interactions were quantitatively evaluated using the fractional inhibitory concentration index (FIC index), which was defined as follows: $\sum$ FIC-MIC $=$ FIC A + FIC B $=($ MIC of drug A in combination/MIC of drug A alone) + (MIC of drug B in combination/MIC of drug B alone). Interpretive criteria used to define the interactions by using MICs endpoints were: synergism, $\Sigma$ FIC $\leq 0.5$; no interaction, $\Sigma$ FIC $>0.5$ but $\leq 4.0$ and antagonism, $\Sigma$ FIC $>4.0$ [21].

\subsection{Galleria mellonella Mucormycosis Model for the Evaluation of the Effect of Antifungal Drugs Combinations}

G. mellonella caterpillars in their final stage of larval development (Provided by the Agricultural Sciences School-Universidad Nacional del Litoral, Argentina) were used. Larvae were classified by body weight and divided into groups of 10 individuals weighting $250 \pm 50 \mathrm{mg}$. In order to establish the appropriate inoculum able to cause, at least $80 \%$ mortality at $48 \mathrm{~h}$ (consistent with recorded mortality in humans) [22] different spore concentration of $R$. microsporum LMDM-165 and R. oryzae LMDM-597 were tested. Inocula concentrations were determined by spore counting in a hemocytometer chamber, adjusted in phosphate-buffered saline (PBS) and confirmed by post infection viable counts. Groups of 10 caterpillars were infected with $10 \mu \mathrm{L}$ of the different inoculum suspensions of each strain, resulting in $10^{3}, 10^{4}, 10^{5}, 10^{6}$, and $10^{7}$ spores/larva. Hamilton syringes (Fisher Scientific, Buenos Aires, Argentina) were used to inject spore suspensions into G. mellonella's hemocoel through the last left proleg. Control groups of 10 caterpillar each were added including an untouched group, a pierced group and an injected with $10 \mu \mathrm{L}$ of PBS group. Larvae were incubated up to seven days at $37^{\circ} \mathrm{C}$, and survival was recorded daily. End points were considered when larvae did not respond to physical pressure. The antifungal treatment model was established by replicating the described experiments but modifying the number of doses of $\mathrm{AMB}$ and adding a toxicity control group. We chose $\mathrm{AMB}$ to test the survival increase (comparing with infection control) since this polyene is one of the antifungals of choice to treat Mucormycosis [23] and the most used in South America to treat these mycoses. Preparation of antifungal agents for injection, used doses and tolerability of the treatment in larva of G. mellonella were done following the protocol described by Kloezen et al. [24]. The number of doses necessary to improve the survival at $96 \mathrm{~h}$ post-infection was assessed by evaluating the effect of one, two or three drug doses over the infected caterpillar within $2 \mathrm{~h}, 26 \mathrm{~h}$, and $50 \mathrm{~h}$ post infection also following the procedure described before [24]. Ten $\mu \mathrm{l}$ of each of the tested drug solution, which resulted in a final concentration of $1 \mathrm{mg} / \mathrm{kg}$ for AMB and CSF and $10 \mathrm{mg} / \mathrm{kg}$ for VRC and PSC were inoculated into the last right proleg of each caterpillar. The used concentrations are equivalent to the therapeutic concentrations [23]. The G. mellonella groups which received combined treatments were inoculated with $10 \mu \mathrm{L}$ of a combined drug solution using the lowest antifungal doses where hyphae alterations (HA) were observed (more details in the result section). These doses were used to test the impact of the HA in an in vivo model. The reduction on the tested concentrations were in accordance with the results obtained for R. microsporus LMDM-165 in the in vitro synergism experiments (more detail in the Results section). Experiments were performed in triplicate and repeated three different days with similar results using $10 \mathrm{G}$. mellonella caterpillar per tested condition (total $n=30$ ). These experiments include inoculum establishment, doses, toxicity, single-drug, and combination treatments.

\subsection{Data Analysis}

In vitro susceptibility (MICs and $\Sigma$ FICs) and in vivo data are the results of experiments performed in triplicate and on three separate days. Continuous variables ( $\mathrm{FFICs}$ ) are expressed as arithmetic means while geometric means (GMs) were used to statistically compare MIC results. The off-scale 
MICs were converted to the next concentration up or down and were included in the analysis. To establish susceptibility differences between strains, MICs values were approximated to a normal distribution by transforming them to $\log _{2}$ values. The significance levels of susceptibilities differences were determined by Student's $t$-test (unpaired, unequal variance). $P$ values $\leq 0.05$ were considered significant. Kaplan-Meier survival analysis was used to compare the time of death for each group of caterpillars in the G. mellonella infection and treatment models. $P$ values were calculated by the $\log$ rank (Mantel-Cox) test. A $P$ value $\leq 0.05$ was considered significant. Statistical analyses were performed with GraphPad Prism, version 7.03 (GraphPad Software, Inc., La Joya, CA, USA).

\section{Results}

\subsection{Individual Drug and Combined Susceptibility Testing}

The in vitro activities of the tested antifungal drugs are summarized in Table 1. As expected, AMB and PSC were the most active drugs (both drugs showed GM $1.03 \mathrm{mg} / \mathrm{L}$ for all isolates). However, when $R$. microsporus $(n=15)$ MICs were compared with those of other Mucorales isolates $(n=10)$ species-specific differences were found for AMB but not for PSC. For the polyene, R. microsporus showed statistically higher MICs than the other species $(1.45 \mathrm{mg} / \mathrm{L}$ and $0.62 \mathrm{mg} / \mathrm{L}$, respectively; $P=0.0091$ ). Elevated VRC and CSF MICs were obtained for all the isolates although slightly significant lower VRC MIC GMs were observed for R. microsporus than for the other Mucorales $(4.59 \mathrm{mg} / \mathrm{L}$ vs. $8.00 \mathrm{mg} / \mathrm{L}$, respectively; $P=0.0295)$. The $\Sigma F I C s$ varied according to the used combination. Briefly, for VRC + PSC only four strains and for VRC + AMB three strains showed $\Sigma F I C=0.5$ (borderline synergism) for each combination and only one L. ramosa strain showed $\Sigma F I C=0.31$ for VRC + PSC combination. The VRC + CSF combination exhibited $\Sigma$ FIC interpreted as having no interaction for all the tested strains with $\Sigma$ FIC values averaging 1.45.

Microscopic HA (defined as small, rounded, compact hyphal forms, as compared to the growth control) were observed for some isolates when confronted against VRC + AMB, VRC + PSC and VRC + CSF combinations (Figure 1). This effect resembles the minimal effective concentration (MEC) reported for filamentous Ascomycetes growing in the presence of an echinocandin drug $[20,25]$. It was observed in $48 \%$ (12 out of 25 strains), $28 \%(n=7)$ and $36 \%(n=9)$ of the tested strains when confronted against VRC + PSC, VRC + AMB, and VRC + CSF combinations, respectively (Table 1). No microscopic HA were seen for any of the tested strains when individual drugs were tested.

\subsection{Galleria mellonella Infection and Antifungal Treatment Model}

G. mellonella mucormycosis model was used to evaluate if the observed microscopic HA have any in-vivo impact. To do so, we choose a R. microsporus (LMDM-165) and a R. oryzae (LMDM-597) as infective strains, as they showed the exact MIC and $\Sigma$ FIC values for all the individual drugs and combinations but different microscopic behavior when confronted against the tested drugs combinations. R. microsporus LMDM-165 showed $\Sigma$ FICs interpreted as having no interaction but showed the mentioned microscopic HA for all the tested combinations. On the other hand, R. oryzae LMDM-597 exhibited the same $\Sigma$ FICs but no HA were observed. The selected inoculum for the mucormycosis model was $10^{3}$ spores/larvae of both strains since $80 \%$ mortality was obtained at $48 \mathrm{~h}$ post-challenge (higher spore concentrations produced 100\% mortality between the first and second day post-infection) (Figure 2). The number of AMB doses necessary to increase the survival at $96 \mathrm{~h}$ post-infection was assessed. A significant increase in survival was observed when comparing one and two AMB doses $(P=0.033)$ while no survival changes were seen when three AMB doses were used $(P=0.161)$ (Figures 2 and 3$)$. Thus, two doses was chosen as the ideal treatment model to be used. The same number of doses was used for all the tested treatments. Toxicity control groups showed a $100 \%$ survival (data not shown in order to reduce the complexity of Figure 2). 
A

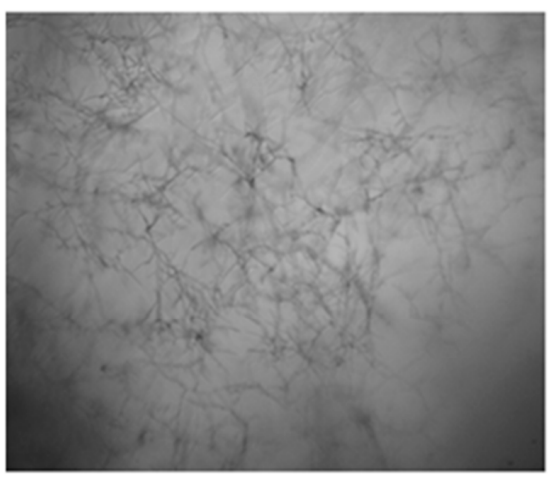

$\mathrm{C}$

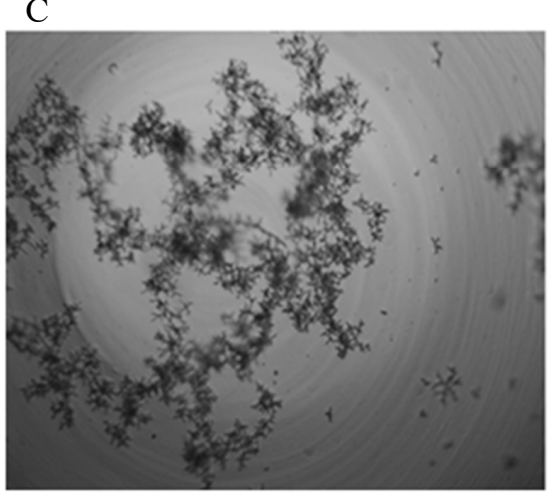

E
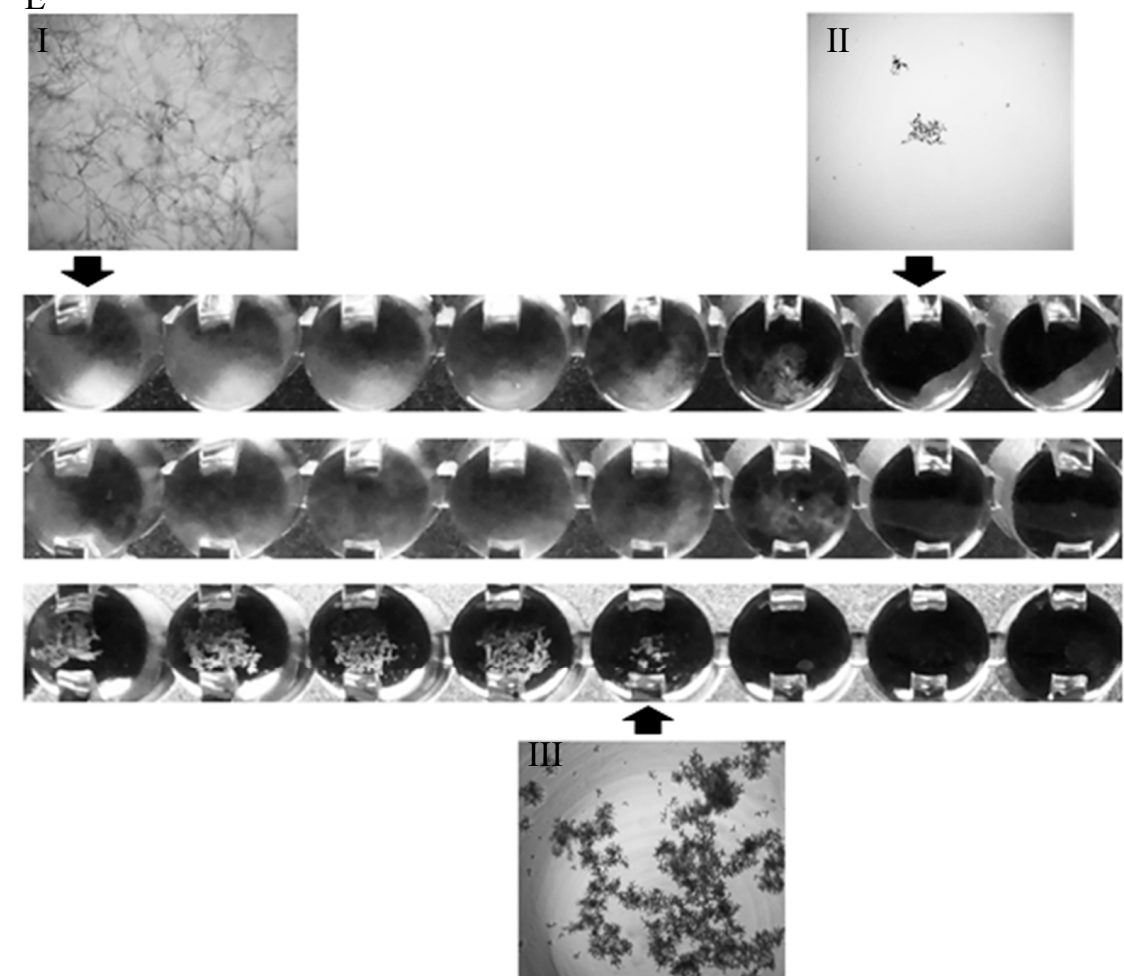

Figure 1. Light microphotography $(50 \times)$ of morphology changes in R. microsporus LMDM-165 observed in combinations of drugs. (A) Growth control; (B) VRC + AMB $(2 \mathrm{mg} / \mathrm{L}+0.06 \mathrm{mg} / \mathrm{L}$, respectively); (C) VRC + PSC ( $2 \mathrm{mg} / \mathrm{L}+0.25 \mathrm{mg} / \mathrm{L}$, respectively); (D) VRC + CSF $(2 \mathrm{mg} / \mathrm{L}+4 \mathrm{mg} / \mathrm{L}$, respectively). (E) Microdilution plates showing AMB alone (upper line: 0.03-4.00 mg/L), VRC alone (middle line, $0.12-16.00 \mathrm{mg} / \mathrm{L}$ ) and VRC + AMB combination (lower line). AMB and VRC MICs are $2 \mathrm{mg} / \mathrm{L}$ and $8 \mathrm{mg} / \mathrm{L}$, respectively. The corresponding microscopic appearance are shown (I: growth control, II: $100 \%$ inhibition and III: Microscopic hyphal alterations).
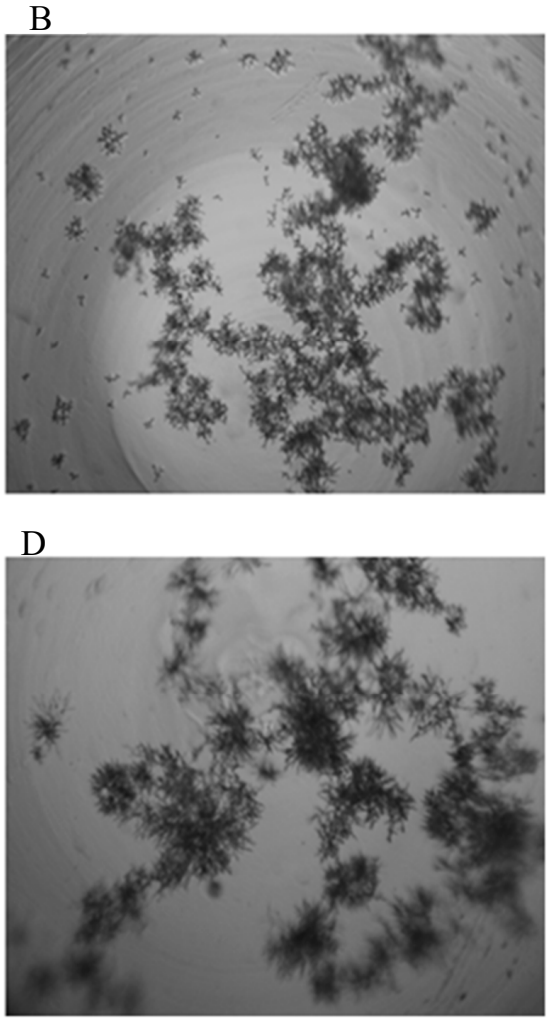

II

的 


\subsection{Evaluation of the Efficacy of the Drug Combinations in the Galleria mellonella Model}

The median survival (days in which $50 \%$ survival was recorded) was one or two days in the untreated control groups infected with LMDM-165 and LMDM-597 strains. When individual drugs (at therapeutic doses) were used, no statistically significant improvement in survival was observed except for the LMDM-165 infected group when treated with CSF $(\mathrm{P}=0.035)$ (Figure 3). Turning to drug combinations, caterpillars infected with $R$. microsporus and $R$. oryzae received a combination of drugs in doses equal to the lowest concentrations where the HA were observed in vitro for the R. microsporus LMDM-165 isolate. Thus, AMB doses were reduced 32 times $(0.03 \mathrm{mg} / \mathrm{kg} /$ day $)$ compared to the usual therapeutic dose. AMB MIC for both strains were $2 \mathrm{mg} / \mathrm{L}$ but the microscopic HA was observed at $0.06 \mathrm{mg} / \mathrm{L}$ when AMB was combined with other antifungals. Similarly, CSF and azole doses were reduced four times $(0.125 \mathrm{mg} / \mathrm{kg} /$ day and $2.5 \mathrm{mg} / \mathrm{kg} /$ day, respectively). For these last antifungals, the HA were observed in wells where the drug concentrations were 4-fold lower than the recorded MICs, respectively. Despite these dose reductions, the median survivals for combinations were higher than for individual drugs for all the tested combinations when the infective agent was $R$. microsporus LMDM-165 (Figure 3).

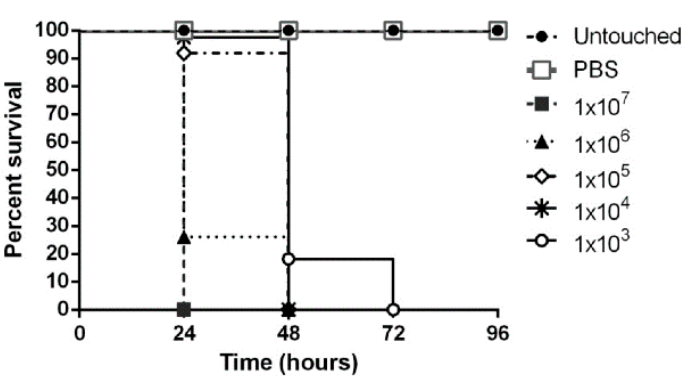

A

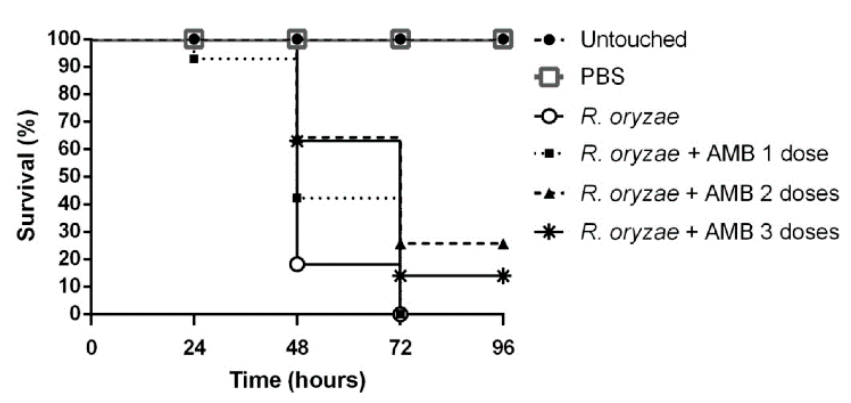

$\mathrm{B}$

Figure 2. Survival curves used to establish the Galleria mellonella model of mucormycosis. (A) Infection model establishment by using different $R$. oryzae LMDM-597 inocula; (B) Mucormycosis treatment model using $R$. oryzae and different number of AMB doses ( $1 \mathrm{mg} / \mathrm{kg} /$ day).

These survival improvements where statistically significant when VRC + AMB and VRC + CSF treatments were compared with untreated and AMB treatment group $(P=0.0087$ and $P=0.0081$ vs. untreated and $P=0.040$ and $P=0.045$ vs. AMB treatment group, respectively). On the contrary, when $R$. oryzae infected larvae were treated with combinations, no survival improvement was seen compared to the untreated or the individual drugs groups (all the $P>0.05$ ) (Figure 3 ). None of the drugs alone or in combinations showed toxic effect on the larvae at the used concentrations (data on the toxicity groups are not shown). 
A

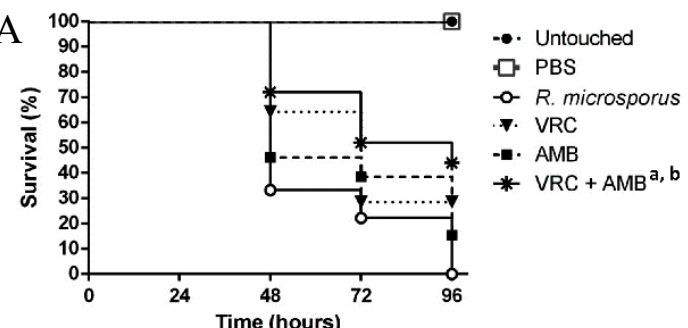

C

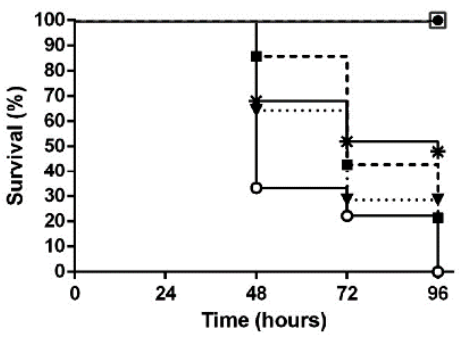

-•. Untouched

$\square$ PBS

- R. microsporus

. V. VRC

-m. $\mathrm{CSF}^{\mathrm{a}}$

* VRC + CSF a, b
B

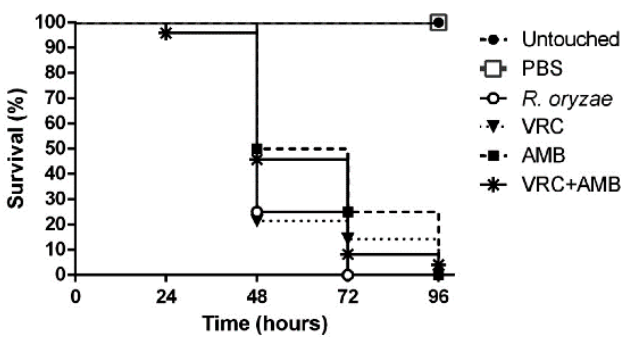

$\mathrm{D}$

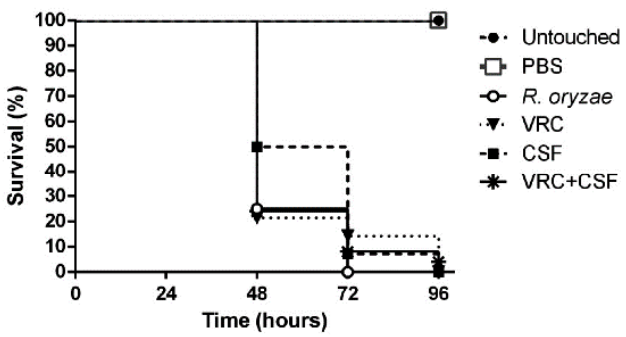

$\mathrm{F}$

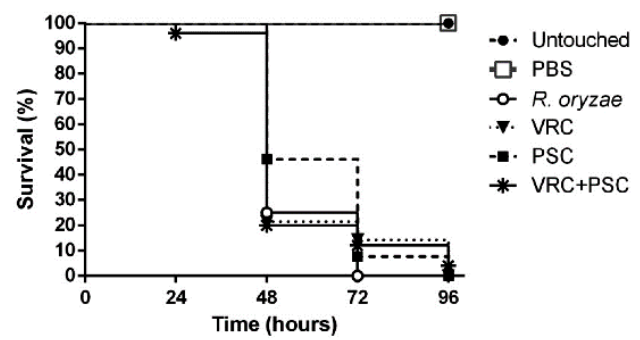

E

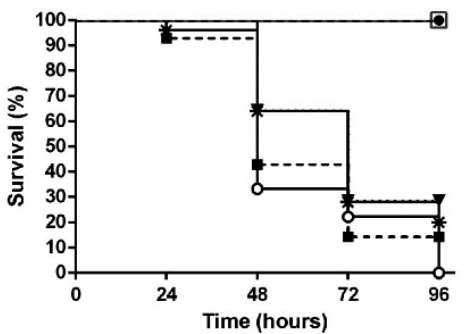

-. Untouched $\square$ PBS

- R. microsporus

-. VRC

-. PSC

* VRC+PSC

Figure 3. Survival curves of $G$. mellonella infected with $R$. microspores LMDM-165 treated with two doses of: (A) VRC (10 mg/kg/day), AMB (1 mg/kg/day) and VRC + AMB $(2.5 \mathrm{mg} / \mathrm{kg} /$ day + $0.03 \mathrm{mg} / \mathrm{kg} /$ day); (C) VRC (10 mg/kg/day), CSF (0.5 mg/kg/day) and VRC + CSF $(2.5 \mathrm{mg} / \mathrm{kg} /$ day + $0.125 \mathrm{mg} / \mathrm{kg} /$ day); (E) VRC (10 mg/kg/day), PSC (10 mg/ kg/day) and VRC + PSC (2.5 mg/kg/day + $2.5 \mathrm{mg} / \mathrm{kg} /$ day). Infections with R. oryzae LMDM-597 treated with: (B) VRC (10 mg/kg/day), AMB $(1 \mathrm{mg} / \mathrm{kg} /$ day $)$ and VRC + AMB $(2.5 \mathrm{mg} / \mathrm{kg} /$ day $+0.03 \mathrm{mg} / \mathrm{kg} /$ day $) ;($ D) VRC $(10 \mathrm{mg} / \mathrm{kg} /$ day $)$, CSF $(0.5 \mathrm{mg} / \mathrm{kg} /$ day) and VRC + CSF $(2.5 \mathrm{mg} / \mathrm{kg} /$ day $+0.125 \mathrm{mg} / \mathrm{kg} /$ day $)($ F $)$ VRC (10 mg/kg/day), PSC (10 mg/kg/day) and VRC + PSC (2.5 mg/ kg/day $+2.5 \mathrm{mg} / \mathrm{kg} /$ day $).{ }^{\text {a }}$ Statistically significant improvement in survival when compared with untreated. ${ }^{b}$ Statistically significant improvement in survival when compared with AMB.

\section{Discussion}

Mucormycosis mortality rate has remained over $40 \%$ for years [22,26,27]. Effective treatment of these mycoses depends on quick diagnosis, surgical debridement, reducing or eliminating risk factors and early antifungal treatment [27]. One of the main advances in mucormycosis treatment was the shift from AMB deoxycholate to AMB lipid formulations [6,28,29]. Also, echinocandins and combination treatments were tested with promissory results when using animal models but less encouraging outcomes were obtained in clinical scenarios [3,6,30]. In 2014, Kontoyiannis et al. published a prospective clinical trial where monotherapy (mainly lipid-based AMB) was used in $60 \%$ of the cases while combination therapy (AMB+PSC and AMB+echinocandins) was used in the remaining patients. They concluded that it is still more important a prompt treatment initiation to improve survival than using a single or combination therapy [3].

Most of the published reports where treatment effectiveness was evaluated did not identify all the strains to species or variety level $[3,9,31]$. Our data suggest that in vitro and in vivo susceptibility to a particular treatment depends largely on the etiologic agent. We found different behavior even in the 
different former varieties of $R$. microsporus. These results are in accordance with previously reported data [32].

Turning to the in vivo testing of drug combinations, several reports demonstrated its effectiveness using murine models of mucormycosis due to R. oryzae (Gebremariam et al. also used Mucor circinelloides) [5]. However, none performed a previous evaluation of the in vitro activity of the tested combinations $[5-8,10,11]$. In this work, we firstly evaluated the in vitro activity of the tested combination and later tested them in a Galleria mellonella model of mucormycosis using two Rhizopus species with identical MIC and $\Sigma$ FIC values but with different microscopic morphology after drug exposure. We used an infection model similar to the one published by Kaerger et al. [33] but using a higher incubation temperature $\left(37^{\circ} \mathrm{C}\right.$ vs. $\left.30^{\circ} \mathrm{C}\right)$ and a lower inocula $\left(10^{3}\right.$ spores/larvae vs. $10^{6}$ spores/larvae). The rationale of these changes was the fact that most of the published models of fungal infections used $37^{\circ} \mathrm{C}$ as incubation temperature [34-38]. However, as described by Kaerger et al. [33], thermotolerant Rhizopus species (human pathogens) spread faster within the caterpillar at higher temperature. Thus, inocula were reduced in our model to circumvent this issue and allow us to evaluate differences in treatment efficacy.

We decided to test combinations including VRC (VRC + CSF, VRC + AMB, and VRC + PSC) since these combinations partially fulfil what Spellberg et al. considered as characteristics that drugs combinations may have to be studied as potential options of mucormycosis treatment [4]. Thus, these drugs are agents already approved and with good efficacy and safety. However, there is no data regarding survival improvement in animal models of mucormycosis. In this work, the tested combinations improve caterpillar survival in a strain depending manner (higher survival in $R$. microsporus than in R. oryzae infected larvae). We also chose to test combinations of drugs with VRC based in reports where combinations that included azole drugs showed to be synergistic against azole resistant fungi [39-41] and that the pre-exposure to triazoles enhanced AMB activity against Rhizopus spp. [42]. The results shown here demonstrate that combinations of drugs that included VRC (+ AMB and + CSF) produce a morphological change in the hyphae of some Mucorales strains (not observed when treated with the antifungals alone). When these morphological modifications were observed, a better survival of $G$. mellonella caterpillars was obtained. Thus, it seems that microscopically observed HA correlates better with survival improvement than $\Sigma$ FICI. The substantial reduction, especially in AMB doses, would signify a concomitant reduction in toxicity in a hypothetical combined treatment. Moreover, considering that some authors showed that Mucormycosis should be taken into account in patients receiving VRC as Aspergillosis prophylaxis [43-45], VRC plus a low AMB dose should be studied as a preemptive treatment option for both Aspergillosis and Mucormycosis, especially in immunosuppressed patients with diabetes and/or malnutrition [43].

When using VRC + CSF in the G. mellonella model, a survival improvement was also seen. It is difficult to explain how VRC is able to improve the performance of AMB and CSF when combined. However, earlier reports have demonstrated that CSF enhances the activity of other drugs against intrinsic echinocandin resistant fungi as Cryptococcus spp. and Fusarium spp. [46,47]. Similarly, combinations that included azole drugs showed to be synergistic against azole resistant fungi $[39,41,48]$. On the contrary, a recent work demonstrated that micafungin did not enhance the activity of isavuconazole in a murine model of mucormycosis [5]. However, this lack of improvement in the survival rate would be also related with the limited efficacy seen for this newly commercialized azole reported by Maurer et al. using a G. mellonella model of mucormycosis [49].

This work would be a starting point to understand how antifungal combinations alter Mucorales hyphae and contribute to G. mellonella survival improvement. However, further work is necessary to confirm the clinical applicability of our observations, to evaluate the relative concentrations and the pharmacodynamics of the tested antifungals within caterpillar tissues and to clarify the molecular mechanism involved in the alteration of Mucorales hyphae. 
Author Contributions: Conceptualization, G.G.-E.; Formal analysis, S.G. and G.G.-E.; Funding acquisition, S.G. and G.G.-E.; Investigation, D.M., F.L. and C.D.; Methodology, S.G.; Resources, R.G.V., E.D.V., and G.G.; Supervision, S.G. and G.G.-E.; Writing—original draft, D.M.; Writing—review and editing, G.G.-E.

Funding: This research was founded by the Science, Technology and Productive Innovation Ministry (MinCyT; Argentina) grant PICT2013/1571 to G.G.-E. and S.G.

Acknowledgments: D.M. and F.L. have a PhD fellowship from CONICET (Argentina). C.D. have postdoctoral fellowships from CONICET. D.M. received an Overseas Scholarship from the British Society for Antimicrobial Chemotherapy (Overseas Scholarship BSAC 2017-0022).

Conflicts of Interest: The authors declare no conflict of interest. The funders had no role in the design of the study, in the collection, analyses, or interpretation of data; in the writing of the manuscript, or in the decision to publish results.

\section{References}

1. Miceli, M.H.; Kauffman, C.A. Isavuconazole: A New Broad-Spectrum Triazole Antifungal Agent. Clin. Infect. Dis. 2015, 61, 1558-1565. [CrossRef]

2. Skiada, A.; Lass-Floerl, C.; Klimko, N.; Ibrahim, A.; Roilides, E.; Petrikkos, G. Challenges in the diagnosis and treatment of mucormycosis. Med. Mycol. 2018, 56, 93-101. [CrossRef] [PubMed]

3. Kontoyiannis, D.P.; Azie, N.; Franks, B.; Horn, D.L. Prospective antifungal therapy (PATH) alliance((R)): Focus on mucormycosis. Mycoses 2014, 57, 240-246. [CrossRef] [PubMed]

4. Spellberg, B.; Ibrahim, A.; Roilides, E.; Lewis, R.E.; Lortholary, O.; Petrikkos, G.; Kontoyiannis, D.P.; Walsh, T.J. Combination therapy for mucormycosis: Why, what, and how? Clin. Infect. Dis. 2012, 54 (Suppl. 1), S73-S78. [CrossRef] [PubMed]

5. Gebremariam, T.; Wiederhold, N.P.; Alqarihi, A.; Uppuluri, P.; Azie, N.; Edwards, J.E., Jr.; Ibrahim, A.S. Monotherapy or combination therapy of isavuconazole and micafungin for treating murine mucormycosis. J. Antimicrob. Chemother. 2017, 72, 462-466. [CrossRef] [PubMed]

6. Ibrahim, A.S.; Gebremariam, T.; Fu, Y.; Edwards, J.E., Jr.; Spellberg, B. Combination echinocandin-polyene treatment of murine mucormycosis. Antimicrob. Agents Chemother. 2008, 52, 1556-1558. [CrossRef] [PubMed]

7. Ibrahim, A.S.; Gebremariam, T.; Luo, G.; Fu, Y.; French, S.W.; Edwards, J.E., Jr.; Spellberg, B. Combination therapy of murine mucormycosis or aspergillosis with iron chelation, polyenes, and echinocandins. Antimicrob. Agents Chemother. 2011, 55, 1768-1770. [CrossRef]

8. Lewis, R.E.; Ben-Ami, R.; Best, L.; Albert, N.; Walsh, T.J.; Kontoyiannis, D.P. Tacrolimus enhances the potency of posaconazole against Rhizopus oryzae in vitro and in an experimental model of mucormycosis. J. Infect. Dis. 2013, 207, 834-841. [CrossRef]

9. Reed, C.; Bryant, R.; Ibrahim, A.S.; Edwards, J., Jr.; Filler, S.G.; Goldberg, R.; Spellberg, B. Combination polyene-caspofungin treatment of rhino-orbital-cerebral mucormycosis. Clin. Infect. Dis. 2008, 47, 364-371. [CrossRef]

10. Spellberg, B.; Fu, Y.; Edwards, J.E., Jr.; Ibrahim, A.S. Combination therapy with amphotericin B lipid complex and caspofungin acetate of disseminated zygomycosis in diabetic ketoacidotic mice. Antimicrob. Agents Chemother. 2005, 49, 830-832. [CrossRef]

11. Sugar, A.M.; Liu, X.P. Combination antifungal therapy in treatment of murine pulmonary mucormycosis: Roles of quinolones and azoles. Antimicrob. Agents Chemother. 2000, 44, 2004-2006. [CrossRef] [PubMed]

12. Dolatabadi, S.; Walther, G.; van den Ende, A.H.G.G.; de Hoog, G.S. Diversity and delimitation of Rhizopus microsporus. Fungal Divers. 2014, 64, 145-164. [CrossRef]

13. Ribes, J.A.; Vanover-Sams, C.L.; Baker, D.J. Zygomycetes in human disease. Clin. Microbiol. Rev. 2000, 13, 236-301. [CrossRef] [PubMed]

14. Schipper, M.A.A.; Staplers, J.A. A revision of the genus Rhizopus. II. The Rhizopus microsporus group. Stud. Mycol. 1984, 25, 20-34.

15. Schipper, M. A revision of the genus Rhizopus. I. The Rhizopus stolonifer group and Rhizopus oryzae. Stud. Mycol. 1984, 25, 1-19.

16. Machouart, M.; Larche, J.; Burton, K.; Collomb, J.; Maurer, P.; Cintrat, A.; Biava, M.F.; Greciano, S.; Kuijpers, A.F.; Contet-Audonneau, N.; et al. Genetic identification of the main opportunistic Mucorales by PCR-restriction fragment length polymorphism. J. Clin. Microbiol. 2006, 44, 805-810. [CrossRef] [PubMed] 
17. Vitale, R.G.; Afeltra, J.; Meis, J.F.; Verweij, P.E. Activity and post antifungal effect of chlorpromazine and trifluopherazine against Aspergillus, Scedosporium and zygomycetes. Mycoses 2007, 50, 270-276. [CrossRef] [PubMed]

18. Walther, G.; Pawlowska, J.; Alastruey-Izquierdo, A.; Wrzosek, M.; Rodriguez-Tudela, J.L.; Dolatabadi, S.; Chakrabarti, A.; de Hoog, G.S. DNA barcoding in Mucorales: An inventory of biodiversity. Persoonia 2013, 30, 11-47. [CrossRef]

19. White, T.J.; Bruns, T.D.; Lee, S.B.; Taylor, J.W. Amplification and Direct Sequencing of Fungal Ribosomal RNA Genes for Phylogenetics; PCR Protocols: A Guide to Methods and Applications; Innis, M.A., Gelfand, D.H., Sninsky, J.J., White, T.J., Eds.; Academic Press, Inc.: San Diego, CA, USA, 1990.

20. Clinical and Laboratory Standards Institute. Reference Method for Broth Dilution Antifungal Susceptibility Testing of Filamentous Fungi, 3rd ed.; CLSI Standard M38; Clinical and Laboratory Standards Institute: Wayne, PA, USA, 2017.

21. Odds, F.C. Synergy, antagonism, and what the chequerboard puts between them. J. Antimicrob. Chemother. 2003, 52, 1. [CrossRef] [PubMed]

22. Roden, M.M.; Zaoutis, T.E.; Buchanan, W.L.; Knudsen, T.A.; Sarkisova, T.A.; Schaufele, R.L.; Sein, M.; Sein, T.; Chiou, C.C.; Chu, J.H.; et al. Epidemiology and outcome of zygomycosis: A review of 929 reported cases. Clin. Infect. Dis. 2005, 41, 634-653. [CrossRef] [PubMed]

23. Lewis, R.E. Current concepts in antifungal pharmacology. Mayo Clin. Proc. 2011, 86, 805-817. [CrossRef] [PubMed]

24. Kloezen, W.; Parel, F.; Bruggemann, R.; Asouit, K.; Helvert-van, P.M.; Fahal, A.; Mouton, J.; van de Sande, W. Amphotericin B and terbinafine but not the azoles prolong survival in Galleria mellonella larvae infected with Madurella mycetomatis. Med. Mycol. 2017. [CrossRef] [PubMed]

25. Espinel-Ingroff, A. Evaluation of broth microdilution testing parameters and agar diffusion Etest procedure for testing susceptibilities of Aspergillus spp. to caspofungin acetate (MK-0991). J. Clin. Microbiol. 2003, 41, 403-409. [CrossRef] [PubMed]

26. Spellberg, B.; Edwards, J., Jr.; Ibrahim, A. Novel perspectives on mucormycosis: Pathophysiology, presentation, and management. Clin. Microbiol. Rev. 2005, 18, 556-569. [CrossRef] [PubMed]

27. Spellberg, B.; Ibrahim, A.S. Recent advances in the treatment of mucormycosis. Curr. Infect. Dis. Rep. 2010, 12, 423-429. [CrossRef] [PubMed]

28. Gleissner, B.; Schilling, A.; Anagnostopolous, I.; Siehl, I.; Thiel, E. Improved outcome of zygomycosis in patients with hematological diseases? Leuk. Lymphoma 2004, 45, 1351-1360. [CrossRef]

29. Skiada, A.; Lanternier, F.; Groll, A.H.; Pagano, L.; Zimmerli, S.; Herbrecht, R.; Lortholary, O.; Petrikkos, G.L. Diagnosis and treatment of mucormycosis in patients with hematological malignancies: Guidelines from the 3rd European Conference on Infections in Leukemia (ECIL 3). Haematologica 2013, 98, 492-504. [CrossRef]

30. Ibrahim, A.S.; Bowman, J.C.; Avanessian, V.; Brown, K.; Spellberg, B.; Edwards, J.E., Jr.; Douglas, C.M. Caspofungin inhibits Rhizopus oryzae 1,3-beta-D-glucan synthase, lowers burden in brain measured by quantitative PCR, and improves survival at a low but not a high dose during murine disseminated zygomycosis. Antimicrob. Agents Chemother. 2005, 49, 721-727. [CrossRef]

31. Taj-Aldeen, S.J.; Gamaletsou, M.N.; Rammaert, B.; Sipsas, N.V.; Zeller, V.; Roilides, E.; Kontoyiannis, D.P.; Henry, M.; Petraitis, V.; Moriyama, B.; et al. Bone and joint infections caused by mucormycetes: A challenging osteoarticular mycosis of the twenty-first century. Med. Mycol. 2017. [CrossRef]

32. Vitale, R.G.; de Hoog, G.S.; Schwarz, P.; Dannaoui, E.; Deng, S.; Machouart, M.; Voigt, K.; van de Sande, W.W.; Dolatabadi, S.; Meis, J.F.; et al. Antifungal susceptibility and phylogeny of opportunistic members of the order mucorales. J. Clin. Microbiol. 2012, 50, 66-75. [CrossRef]

33. Kaerger, K.; Schwartze, V.U.; Dolatabadi, S.; Nyilasi, I.; Kovacs, S.A.; Binder, U.; Papp, T.; Hoog, S.; Jacobsen, I.D.; Voigt, K. Adaptation to thermotolerance in Rhizopus coincides with virulence as revealed by avian and invertebrate infection models, phylogeny, physiological and metabolic flexibility. Virulence 2015, 6, 395-403. [CrossRef] [PubMed]

34. Alcazar-Fuoli, L.; Buitrago, M.; Gomez-Lopez, A.; Mellado, E. An alternative host model of a mixed fungal infection by azole susceptible and resistant Aspergillus spp strains. Virulence 2015, 6, 376-384. [CrossRef] [PubMed] 
35. Forastiero, A.; Bernal-Martinez, L.; Mellado, E.; Cendejas, E.; Gomez-Lopez, A. In vivo efficacy of voriconazole and posaconazole therapy in a novel invertebrate model of Aspergillus fumigatus infection. Int. J. Antimicrob. Agents 2015, 46, 511-517. [CrossRef]

36. Gago, S.; Garcia-Rodas, R.; Cuesta, I.; Mellado, E.; Alastruey-Izquierdo, A. Candida parapsilosis, Candida orthopsilosis, and Candida metapsilosis virulence in the non-conventional host Galleria mellonella. Virulence 2014, 5, 278-285. [CrossRef] [PubMed]

37. Gago, S.; Serrano, C.; Alastruey-Izquierdo, A.; Cuesta, I.; Martin-Mazuelos, E.; Aller, A.I.; Gomez-Lopez, A.; Mellado, E. Molecular identification, antifungal resistance and virulence of Cryptococcus neoformans and Cryptococcus deneoformans isolated in Seville, Spain. Mycoses 2017, 60, 40-50. [CrossRef] [PubMed]

38. Mesa-Arango, A.C.; Forastiero, A.; Bernal-Martinez, L.; Cuenca-Estrella, M.; Mellado, E.; Zaragoza, O. The non-mammalian host Galleria mellonella can be used to study the virulence of the fungal pathogen Candida tropicalis and the efficacy of antifungal drugs during infection by this pathogenic yeast. Med. Mycol. 2013, 51, 461-472. [CrossRef]

39. Afeltra, J.; Vitale, R.G.; Mouton, J.W.; Verweij, P.E. Potent synergistic in vitro interaction between nonantimicrobial membrane-active compounds and itraconazole against clinical isolates of Aspergillus fumigatus resistant to itraconazole. Antimicrob. Agents Chemother. 2004, 48, 1335-1343. [CrossRef]

40. Gamarra, S.; Rocha, E.M.; Zhang, Y.Q.; Park, S.; Rao, R.; Perlin, D.S. Mechanism of the synergistic effect of amiodarone and fluconazole in Candida albicans. Antimicrob. Agents Chemother. 2010, 54, 1753-1761. [CrossRef]

41. Garcia-Effron, G.; Mellado, E.; Gomez-Lopez, A.; Alcazar-Fuoli, L.; Cuenca-Estrella, M.; Rodriguez-Tudela, J.L. Differences in interactions between azole drugs related to modifications in the 14-alpha sterol demethylase gene (cyp51A) of Aspergillus fumigatus. Antimicrob. Agents Chemother. 2005, 49, 2119-2121. [CrossRef]

42. Bellanger, A.P.; Albert, N.D.; Lewis, R.E.; Walsh, T.J.; Kontoyiannis, D.P. Effect of Preexposure to Triazoles on Susceptibility and Virulence of Rhizopus oryzae. Antimicrob. Agents Chemother. 2015, 59, 7830-7832. [CrossRef]

43. Kontoyiannis, D.P.; Lionakis, M.S.; Lewis, R.E.; Chamilos, G.; Healy, M.; Perego, C.; Safdar, A.; Kantarjian, H.; Champlin, R.; Walsh, T.J.; et al. Zygomycosis in a tertiary-care cancer center in the era of Aspergillus-active antifungal therapy: A case-Control observational study of 27 recent cases. J. Infect. Dis. 2005, 191, 1350-1360. [CrossRef] [PubMed]

44. Marty, F.M.; Cosimi, L.A.; Baden, L.R. Breakthrough zygomycosis after voriconazole treatment in recipients of hematopoietic stem-cell transplants. N. Engl. J. Med. 2004, 350, 950-952. [CrossRef] [PubMed]

45. Siwek, G.T.; Dodgson, K.J.; de Magalhaes-Silverman, M.; Bartelt, L.A.; Kilborn, S.B.; Hoth, P.L.; Diekema, D.J.; Pfaller, M.A. Invasive zygomycosis in hematopoietic stem cell transplant recipients receiving voriconazole prophylaxis. Clin. Infect. Dis. 2004, 39, 584-587. [CrossRef] [PubMed]

46. Arikan, S.; Lozano-Chiu, M.; Paetznick, V.; Rex, J.H. In vitro synergy of caspofungin and amphotericin B against Aspergillus and Fusarium spp. Antimicrob. Agents Chemother. 2002, 46, 245-247. [CrossRef] [PubMed]

47. Franzot, S.P.; Casadevall, A. Pneumocandin L-743,872 enhances the activities of amphotericin B and fluconazole against Cryptococcus neoformans in vitro. Antimicrob. Agents Chemother. 1997, 41, 331-336. [CrossRef] [PubMed]

48. Dannaoui, E.; Afeltra, J.; Meis, J.F.; Verweij, P.E. In vitro susceptibilities of zygomycetes to combinations of antimicrobial agents. Antimicrob. Agents Chemother. 2002, 46, 2708-2711. [CrossRef] [PubMed]

49. Maurer, E.; Hortnagl, C.; Lackner, M.; Grassle, D.; Naschberger, V.; Moser, P.; Segal, E.; Semis, M.; Lass-Florl, C.; Binder, U. Galleria mellonella as a model system to study virulence potential of mucormycetes and evaluation of antifungal treatment. Med. Mycol. 2018. [CrossRef]

(C) 2019 by the authors. Licensee MDPI, Basel, Switzerland. This article is an open access article distributed under the terms and conditions of the Creative Commons Attribution (CC BY) license (http:/ / creativecommons.org/licenses/by/4.0/). 